Marquette University

e-Publications@Marquette

$1-1-2004$

\title{
Crystallographic Distinction between "Contact" and "Separated" Ion Pairs: Structural Effects on Electronic/ESR Spectra of Alkali-Metal Nitrobenzenides
}

\author{
M. G. Davlieva \\ University of Houston \\ Jian-Ming Lü \\ University of Houston \\ Sergey V. Lindeman \\ Marquette University, sergey.lindeman@marquette.edu \\ Jay K. Kochi \\ University of Houston
}

Accepted version. Journal of the American Chemical Society, Vol. 126, No. 14 (2004): 4557-4565.

DOI. (C) 2004 American Chemical Society. Used with permission.

Sergey V. Lindeman was affiliated with the University of Houston at the time of publication. 
Marquette University

\section{e-Publications@Marquette}

\section{Chemistry Faculty Research and Publications/College of Arts and Sciences}

This paper is NOT THE PUBLISHED VERSION; but the author's final, peer-reviewed manuscript. The published version may be accessed by following the link in th citation below.

Journal of the American Chemical Society, Vol. 126, No. 14 (March 20, 2004): 4557-4565. DOI. This article is (C) American Chemical Society and permission has been granted for this version to appear in ePublications@Marquette. American Chemical Society does not grant permission for this article to be further copied/distributed or hosted elsewhere without the express permission from American Chemical Society.

\section{Crystallographic Distinction between "Contact" and "Separated" Ion Pairs: Structural Effects on Electronic/ESR Spectra of Alkali-Metal Nitrobenzenides}

Milya G. Davlieva

Department of Chemistry, University of Houston, Houston, Texas

Jian-Ming Lü

Department of Chemistry, University of Houston, Houston, Texas

Sergey V. Lindeman

Department of Chemistry, University of Houston, Houston, Texas

Jay K. Kochi

Department of Chemistry, University of Houston, Houston, Texas

\section{Abstract}

The classic nitrobenzene anion-radical ( $\mathbf{N B}^{-\bullet}$ or nitrobenzenide) is isolated for the first time as pure crystalline alkali-metal salts. The deliberate use of the supporting ligands 18 -crown- 6 and 
[2.2.2]cryptand allows the selective formation of contact ion pairs designated as (crown) $\mathrm{M}^{+} \mathbf{N B}^{-\bullet}$, where $\mathrm{M}^{+}=\mathrm{K}^{+}, \mathrm{Rb}^{+}$, and $\mathrm{Cs}^{+}$, as well as the separated ion pair $\mathrm{K}(\text { cryptand })^{+} \mathrm{NB}^{-\bullet}-$ both series of which are structurally characterized by precise low-temperature X-ray crystallography, ESR analysis, and UV-vis spectroscopy. The unusually delocalized structure of $\mathbf{N B}^{-\bullet}$ in the separated ion pair follows from the drastically shortened $\mathrm{N}-\mathrm{C}$ bond and marked quinonoidal distortion of the benzenoid ring to signify complete (95\%) electronic conjugation with the nitro substituent. On the other hand, the formation of contact ion pairs results in the substantial decrease of electronic conjugation in inverse order with cation size $\left(\mathrm{K}^{+}>\mathrm{Rb}^{+}\right)$owing to increased localization of negative charge from partial $\left(\mathrm{NO}_{2}\right)$ bonding to the alkali-metal cation. Such a loss in electronic conjugation (or reverse charge transfer) may be counterintuitive, but it is in agreement with the distribution of odd-electron spin electron density from the ESR data and with the hypsochromic shift of the characteristic absorption band in the electronic spectra. Most importantly, this crystallographic study underscores the importance of ion-pair structure on the intrinsic property (and thus reactivity) of the component ions - as focused here on the nitrobenzenide anion.

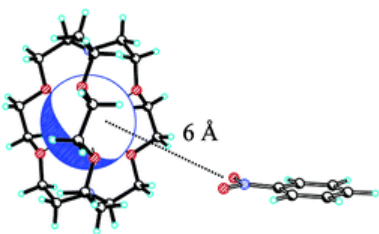

$\mathrm{K}$ (cryptand) ${ }^{+} \mathrm{PhNO}_{2}{ }^{-}$ (separated ion pair)

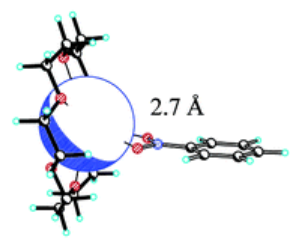

(crown) $\mathrm{K}^{+\cdots} \mathrm{O}_{2} \mathrm{NPh}$ (contact ion pair)

\section{Introduction}

The reactivities of many complex organic and organometallic ions are strongly modulated, particularly in organic solvents, by the competing formation of both contact ion pairs (CIP) as well as separated ion pairs (SIP). ${ }^{1,2}$ Although various spectroscopic techniques including NMR, IR, ESR, UV-vis, etc., have been brought to bear on the identification of various CIPs and SIPs, ${ }^{1-3}$ as well as on their polynuclear aggregations, ${ }^{4}$ the precise elucidation of those structural factors responsible for reactivity changes remains a continuing experimental challenge. Indeed, the ultimate structural tool of single-crystal X-ray crystallography has been (by and large) only sporadically utilized in a rather unsystematic manner. $\underline{5}$

In this study, we address the structural changes of organic anions attendant upon CIP and SIP formation and, in particular, those dealing with the comparative structures of paramagnetic anions because such organic anion-radicals will allow the (negative) charge distribution as well as the (odd) electron-spin density to be independently/simultaneously probed by X-ray crystallography and ESR spectroscopy, respectively. Accordingly, we focus here on a single category of classic anions derived from the 1-electron reduction of various nitrobenzenes in which the spectroscopic changes in the ESR and UV-vis spectra of the resulting nitrobenzene anion-radical (or nitrobenzenide) have been extensively monitored in numerous investigations, especially with regard to these spectral parameters in this chromophoric unit that is comprised of different ion-pair assemblies, briefly summarized as follows. 


\section{ESR Studies of Nitrobenzenide Ion Pairs.}

The persistent anion-radical of nitrobenzene was first prepared in situ via sodium metal (mirror) reduction in 1,2-dimethoxyethane (DME), and the pioneering ESR investigation by Weissman and coworkers $\underline{6}$ was further elaborated by Ward $\underline{7}$ (potassium reduction in DME), Geske and Maki ${ }^{-}$(cathodic reduction in acetonitrile $/ n-\mathrm{Pr}_{4} \mathrm{~N}^{+} \mathrm{ClO}_{4}^{-}$buffer), and Smentowski and Stevenson ${ }^{9}$ (lithium, sodium, and potassium reductions in liquid ammonia at -30 and $-78{ }^{\circ} \mathrm{C}$ ). Of particular relevance to this study are the theoretical calculations of Rieger and Fraenkel, $\underline{10}$ who identified the solvent effect on the hyperfine splittings with changes in the magnitude of the Coulomb integral for the oxygen atoms of nitrobenzene anion-radical $\mathbf{N B}^{-\bullet}$ (in DMF and $\mathrm{MeCN}$ ), and a similar rationale was applied to ion pairs with lithium, sodium, and potassium countercations. $\frac{11}{1}$ The effects of CIP formation and solvation on the ESR spectra of nitrobenzene anion-radical were scrutinized by Ling and Gendell, $\underline{13}$ who found the nitrogen hyperfine splitting in DME solutions to increase inversely with counterion size - being $10.80 \mathrm{G}$ in the presence of $\mathrm{Cs}^{+}$and rising monotonically to $11.55 \mathrm{G}$ in the presence of $\mathrm{Li}^{+}$(relative to $10.15 \mathrm{G}$ in the absence of an alkali-metal cation). At the same time, the proton hyperfine splitting for the parahydrogen decreased only slightly, while those for the meta- and ortho-hydrogens were essentially unaffected, from which Ling and Gendell concluded that the perturbation of electron-spin distribution over the nitrobenzenide anion increases from $\mathrm{Cs}^{+}$to $\mathrm{Li}^{+}$to reflect the transfer of electron density from the phenyl ring to the conjugated nitro group under strong electrostatic influences. ${ }^{13}$ Although various aspects of the reductive behavior of nitrobenzene have also been extensively studied,,$\frac{14-17}{}$ the structures of nitrobenzenide contact ion pairs have been consistently interpreted to result from the simple Coulombic attraction between the positively charged countercation and the overall negative charge density concentrated on the nitro group. $\frac{18-21}{1}$ As such, the chemical reactivity of nitrobenzene anion-radical toward electrophilic reagents such as tert-butyl iodide was simply attributed to the strength of the interionic (electrostatic) association. $\underline{22}$

\section{UV-Vis Studies of Nitrobenzenide Ion Pairs.}

The reported changes in the UV-vis spectrum of nitrobenzene anion-radical and its sensitivity to CIP formation are controversial. Thus, Kemula and Sioda $\underline{23}$ found a pair of UV bands at $\lambda_{\max }=435$ and 465 $\mathrm{nm}$ (both with $\varepsilon \cong 1500 \mathrm{M}^{-1} \mathrm{~cm}^{-1}$ ) for nitrobenzenide anion prepared polarographically in DMF, and similar spectral results were reported by Tsubomura and co-workers ${ }^{24}$ when nitrobenzene was reduced with potassium in DME but with an additional band at $560 \mathrm{~nm}$. By contrast, George and coworkers 25 identified only a single absorption at $440 \mathrm{~nm}$ as being characteristic of nitrobenzenide anion, and the other spectral bands were ascribed to byproducts of further chemical reduction (among which were the anion-radical and dianion of nitrosobenzene, azobenzene, azoxybenzene, and anilinoazoxybenzene, etc). Although the shape of the band was not discussed, its bathochromic shift with cation size in the order $\mathrm{Li}^{+}(440 \mathrm{~nm}), \mathrm{Na}^{+}(444 \mathrm{~nm})$, and $\mathrm{K}^{+}(470 \mathrm{~nm})$ indicated to them a mixture with "... the ratio of intimate and solvent-separated species ..." varying with solvent and countercation. In the meantime, Chambers and Adams ${ }^{26}$ reported the absorption band at $465 \mathrm{~nm}$ for nitrobenzenide anion in the absence of alkali-metal cations (e.g. $\mathrm{Et}_{4} \mathrm{~N}^{+} \mathrm{ClO}_{4}{ }^{-}$electrolyte in DMF) that exhibited a strong blue shift (up to $427 \mathrm{~nm}$ ) upon the addition of water. Gross and Barnes ${ }^{12 a}$ also reported $\lambda_{\max }=462 \mathrm{~nm}$ for $\mathrm{K}^{+} \mathbf{N B}^{-}$in the solid state. Finally, Suga and Aoyagui 27 found the absorption maximum at $460 \mathrm{~nm}$ of nitrobenzenide anion in both DMF solution containing $n-\mathrm{Bu}_{4} \mathrm{~N}^{+} \mathrm{ClO}_{4}^{-}$and in nitrobenzene $\left(\mathrm{Et}_{4} \mathrm{~N}^{+} \mathrm{ClO}_{4}{ }^{-}\right)$. However, the absorption band of nitrobenzenide anion showed a significant red shift to $\lambda_{\max }=580 \mathrm{~nm}$ 
when the supporting electrolyte of the nitrobenzene solution was replaced with the larger $n$ $\mathrm{Bu}_{4} \mathrm{~N}^{+}$counterion. ${ }^{28}$

\section{Theoretical Studies of Nitrobenzenide Ion Pairs.}

The electrochemical behavior of nitrobenzene has been recently revisited in theoretical (DFT) calculations with self-consistent couplings to a continuum solvation model by Schauer and coworkers. $\underline{29}$ Significant ion-pairing effects were computed, but only minor structural differences were found between the theoretical structures of "solvated" nitrobenzene anion-radical and the corresponding "solvated ion-pair" model of $\mathrm{K}^{+} \mathrm{NB}^{-}$. At most, a slight elongation of $\mathrm{N}-\mathrm{O}$ bonds by 0.7 $\mathrm{pm}$ was computed for the contact ion pair, but no changes beyond $0.3 \mathrm{pm}$ were found for the remainder of the nitrobenzenide structure.

This brief but rather comprehensive summary of the extensive (and sometimes contradictory/confusing) literature on the classic nitrobenzenide anion underscores the inherent weakness in the description of ion-pair structures based solely on spectroscopic evidence. In every case, the paramagnetic anion was generated in situ but not isolated as a pure crystalline salt, and as a result, the ion-pair structure, particularly with regard to interionic separation/coordination and solvation, was simply inferred. As such, the structural conclusions were necessarily based on interpretive spectral analyses because the requisite X-ray crystallographic analyses of anion-radical structures of nitrobenzene have been singularly absent in the extant literature. ${ }^{1 e}$

\section{Results}

Although one-electron reductions by alkali-metal mirrors have represented the customary approach to the preparation of nitrobenzenide anion in situ, we found that this (heterogeneous) method was fraught with experimental difficulties leading to various degrees/types of overreduction and nitrocleavage processes that were not easily controlled. Consequently, all our attempts, including variations of the solvent, temperature, and reaction conditions, of this conceptually direct procedure failed to produce crystalline salts suitable for X-ray crystallography. ${ }^{30}$ Moreover, the controlled cathodic reductions of nitrobenzene were not practicable owing to the subsequent difficulty of quantitatively separating the supporting electrolyte.

\section{Synthesis and Isolation of the Nitrobenzenide Anion as Pure Crystalline Salts.}

An important modification of the metal-mirror method that we found to be critically important for the success of this work utilized a stoichiometric amount of a [2.2.2]-cryptand (precisely identified as 4,7,13,16,21,24-hexaoxa-1,10-diazabicyclo[8.8.8] hexacosane) during the potassium-mirror reduction of nitrobenzene dissolved in THF at room temperature. ${ }^{31}$ The effective encapsulation of the cation by [2.2.2]cryptand ${ }^{32}$ allowed us to "insulate" the nitrobenzene anion-radical from the potassium(cryptand) cation in solvent-separated form. The significantly increased chemical stability of the solution drastically reduced tar (side-product) formation, and most importantly, it promoted crystallization and overall resulted in the ready isolation of the pure ion-separated salt K(cryptand) N $^{-}$

- Furthermore, the presence of the less sterically insulating complexon, 18-crown-6 or simply crown, also provided substantial chemical stabilization of the ion-pair products sufficient to improve their crystallization in the form of a series of contact ion pairs herein identified as (crown) $\mathbf{M}^{+} \mathbf{N B}^{-\bullet}$, where $\mathrm{M}^{+}=\mathrm{K}^{+}, \mathrm{Rb}^{+}$, and $\mathrm{Cs}^{+} . \underline{33}$ 


\section{X-ray Crystallography of Nitrobenzenide Salts.}

\section{A. Structure of Potassium(cryptand) Nitrobenzenide as the Separated Ion Pair.}

The typical interionic interaction of the negatively charged nitrobenzene anion-radical NB $^{-\bullet}$ with the $\mathrm{K}$ (cryptand) counterion is characterized by the wide ion-pair separation of $\mathrm{K}^{+} \ldots{ }^{-} \mathrm{O}_{2} \mathrm{~N}-\mathrm{Ph}$ that exceeds 6 $\AA$. In this "separated" ion pair, ${ }^{3 \mathrm{~b}}$ the potassium cation is efficiently enveloped by the cryptand ligand which completely saturates its 8-coordination sphere with six oxygen centers ( $\mathrm{K}^{+} \ldots \mathrm{O}$ of $2.752-2.881 \AA$ ) and a pair of more weakly bound (trans) nitrogen centers ( $\mathrm{K}^{+} \ldots \mathrm{N}$ of 3.010 and $3.038 \AA$ ) to describe an overall bicapped trigonal prismatic structure (twisted by $11^{\circ}$ ) shown in Figure 1.

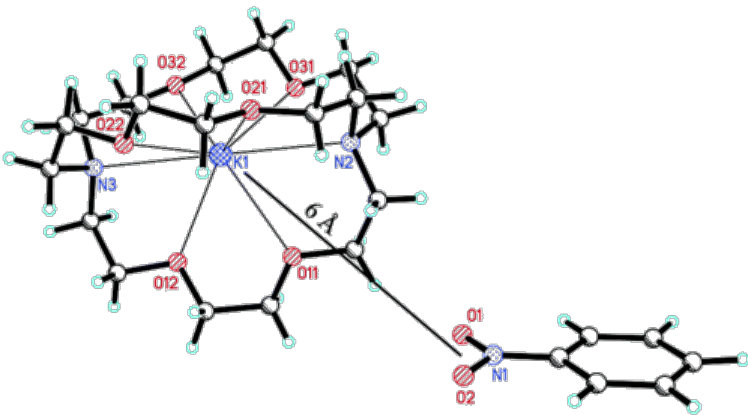

Figure 1 Structure of the separated ion pair in potassium(cryptand) nitrobenzenide with typical interionic $\mathrm{K}^{+} . . \mathrm{NO}_{2}{ }^{-}$separation of $\sim 6 \AA$.

The unit cell of K(cryptand) nitrobenzenide consists of close-packed quasi-spherical cations in which each void is occupied by a nitrobenzene anion-radical (Figure 2). In such a crystal packing, each $\mathrm{NO}_{2}^{-}$center lies within van der Waals distance of the outer lipophilic sheath of $\mathrm{K}(\mathrm{cryptand})^{+}$. As such, this ion-pair structure, coupled with the wide interionic separation between $\mathrm{K}^{+} / \mathrm{NO}_{2}^{-}$centers, is a true (crystalline) representation of what conventionally (and qualitatively) have been considered to be separated ion pairs. ${ }^{1 a}$

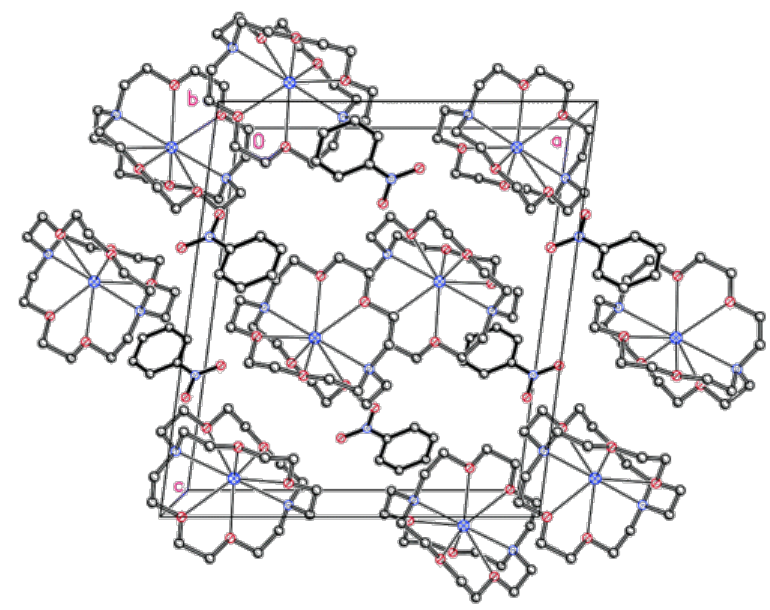

Figure 2. Unit cell of potassium(cryptand) nitrobenzenide showing wide interionic $\mathrm{K}^{+} / \mathrm{NO}_{2}^{-}$distances $(\sim 6 \AA)$ to represent separated ion pairs. 
Table 1. Principal Geometrical Parameters $(\AA)$ of Nitrobenzenide Anion in Contact and Separated Ion Pairs As Compared with the Neutral Nitrobenzene (NB)

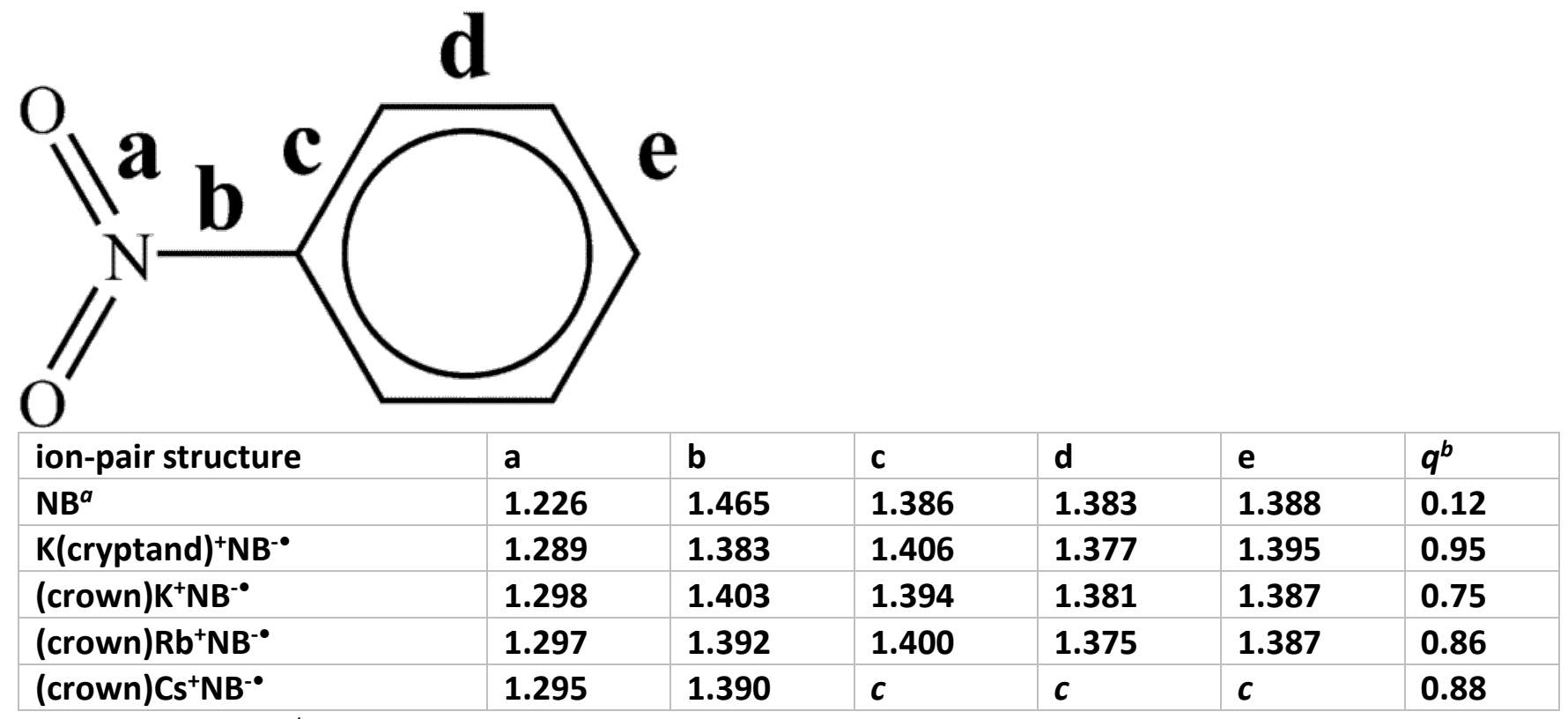

${ }^{a}$ Data from ref $34 .{ }^{b}$ See ref $35 a .{ }^{c}$ No reliable data.

Considerable distortion accompanies the reduction of nitrobenzene to K(cryptand) nitrobenzenide. Although the $\mathbf{N B}^{-\bullet}$ moiety retains its overall coplanar structure, $\underline{\underline{34}}$ it is characterized by three important structural changes including (a) the marked contraction of the $\mathrm{C}-\mathrm{N}$ bond between the nitro group and benzene ring from $1.465 \AA$ to $1.383 \AA$, (b) the concomitant elongation of the $\mathrm{N}-\mathrm{O}$ bonds from $1.226 \AA$ to $1.289 \AA$, and (c) the distinct quinonoidal distortion of the aromatic ring as compared to the structure of the neutral nitrobenzene acceptor ${ }^{34}$ (see Table 1). Such a structure of the "separated" nitrobenzenide anion corresponds to an essentially complete delocalized electronic structure 35 in which the length of the $\mathrm{C}-\mathrm{N}$ bond is close (within experimental error) to the average between the lengths of the unconjugated $\mathrm{C}-\mathrm{N}$ single bond $(1.477 \AA)$ 근 and the $\mathrm{C}==\mathrm{N}$ double bond $(1.280 \AA) . \underline{38}$

\section{B. Coordination of Crown-Ether Ligand to Alkali-Metal Cations To Form Contact Ion} Pairs with Nitrobenzenide Anion.

Coordination of the 18-crown-6 ligand to alkali-metal cations $\left(\mathrm{K}^{+}, \mathrm{Rb}^{+}\right.$, and $\left.\mathrm{Cs}^{+}\right)$can be uniformly described by a general pyramidal (hexapodal) structure,, 39 in which all six oxygen centers constitute the hexagonal basal plane from which the alkali-metal cation is centrally displaced by the vertical distance $(d)$, schematically depicted in $\mathbf{1}$. Such a six-coordination effectively protects the back face of $\mathrm{M}^{+}$, which is then free for ion pairing with nitrobenzenide anion from the open front face as follows.

1

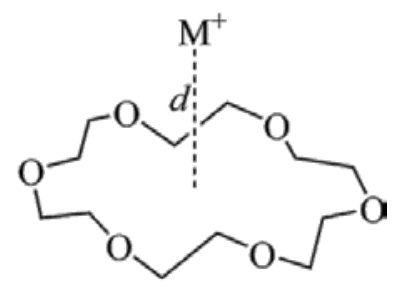

1. Structure of Potassium(crown) Nitrobenzenide. 
In this crown-ether complex, the nitrobenzenide anion symmetrically coordinates the free (open) face of potassium cation via both oxygen centers at close $\mathrm{K}^{+} . . \mathrm{O}$ contacts of $2.743 \AA$ which are significantly shorter than those to the crown-ether ligand (2.772-2.972 $\AA$ ). This (bidentate) coordination of the nitro group is strongly reminiscent of $\sigma$-bonding found with other coplanar chelate metal complexes, $\underline{40}$ since the potassium ion deviates from the plane of the nitro group by a dihedral angle of only $\alpha=15$ deg shown in Figure 3 .

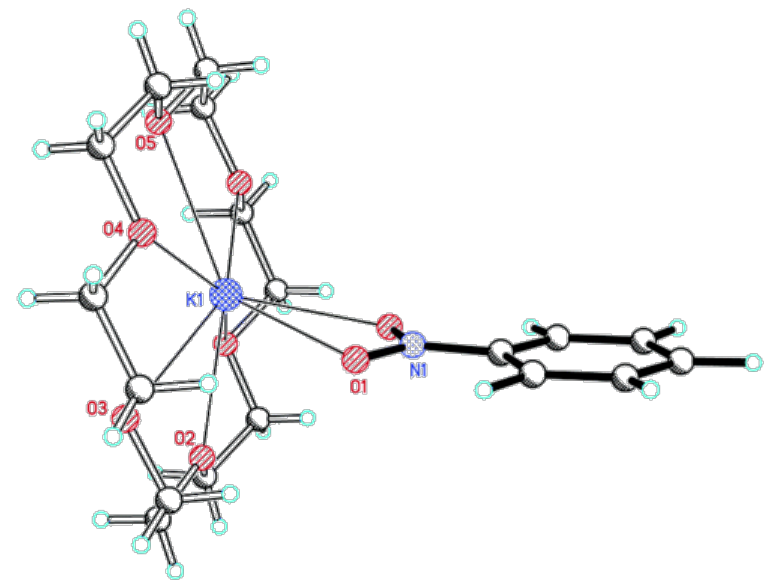

Figure 3 Symmetrical structure of the contact ion pair between (crown) $\mathrm{K}^{+}$and $\mathbf{N B}^{-\bullet}$ anion-radical (crystallographic mirror plane through 02,05 , and $\mathrm{K} 1$ bisecting the nitro group and benzene ring).

The direct coordination of the potassium ion to the anion in potassium(crown) nitrobenzenide can then be described as a contact ion pair. ${ }^{3 \mathrm{~b}}$ In such a nitrobenzenide salt, the relevant $\mathrm{C}-\mathrm{N}$ bond is 2.0 pm longer and there is less quinonoidal distortion (Table 1) than that observed in the separated ion pair with the potassium(cryptand) cation. As a result, the reduced phenyl/ $/ \mathrm{NO}_{2}$ conjugation ${ }^{35}$ is estimated to be only $75 \%$ compared to $95 \%$ extant in the separated ion pair (vide supra).

\section{Structure of Rubidium(crown) Nitrobenzenide.}

The nitrobenzenide anion also achieves chelation with rubidium cation via both its oxygens at short $\mathrm{Rb}^{+} \ldots \mathrm{O}$ distances of 2.872 and $2.930 \AA$. Both distances are closer than the (average) separation from the uncharged crown-ether oxygens ( $\mathrm{Rb}^{+} \ldots \mathrm{O}$ of $2.921-3.120 \AA$ ) , although the rubidium coordination has significant $\pi$-character as indicated by the dihedral angle $\alpha=45^{\circ}$ (Figure 4). In effect, the value of $\alpha$ is midway between pure $\sigma$ binding with $\alpha=0^{\circ}$ and pure $\pi$ binding with $\alpha=90^{\circ}$.

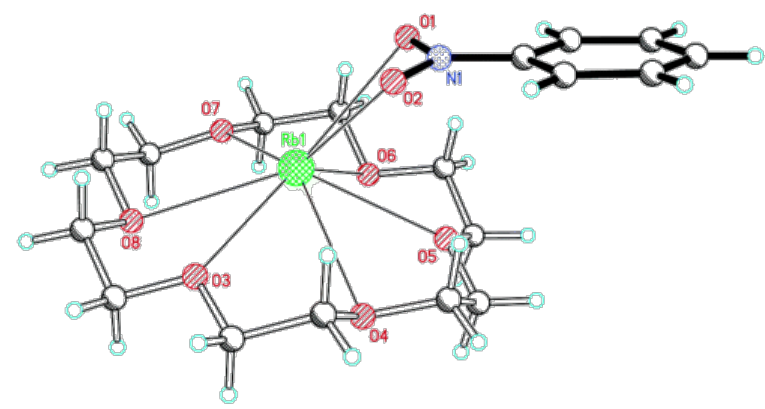

Figure 4 Structure of the contact ion pair between (crown) $\mathrm{Rb}^{+}$and $\mathbf{N B}^{-\bullet}$ anion exhibiting coordination intermediate between pure $\sigma$ - and $\pi$-bindings. 
Indeed, the structure of the nitrobenzenide moiety in the rubidium contact ion pair (crown) $\mathrm{Rb}^{+} \mathrm{NB}^{-\bullet}$ is also intermediate between that in the separated ion pair $\mathrm{K}(\mathrm{cryptand})^{+} \mathbf{N B}^{-\bullet}$ and that in its contact ion pair with (crown) $\mathrm{K}^{+}$insofar as it is described by distortions in molecular geometry (see Table 1).

\section{Structure of Cesium(crown) Nitrobenzenide.}

Progressively increasing the ionic radius of the alkali-metal cation results in its taking on higher coordination number along with the further shift toward $\pi$-coordination to the nitrobenzenide anion-with the $\mathrm{Cs}^{+}$ion deviating from the plane of the adjacent nitro group by an enlarged dihedral angle of $\alpha=55-58^{\circ}$. As a result, the dimeric structure presented in Figure 5 is the dominant form of the contact ion pair (crown) $\mathrm{Cs}^{+} \mathrm{NB}^{-\bullet}$.

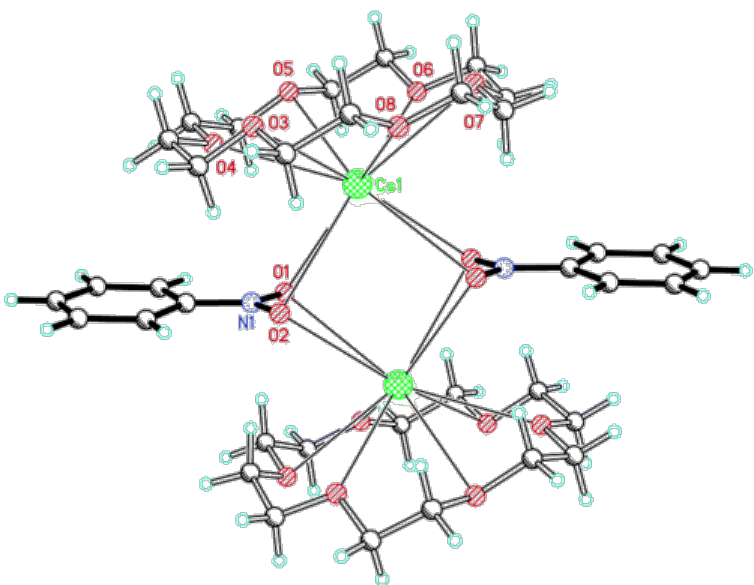

Figure 5 Dimeric ion-pair associate as the dominant structure of cesium(crown) nitrobenzenide salt.

The more diffuse interionic interaction in (crown) $\mathrm{Cs}^{+} \mathbf{N B}^{-}$is reflected in the further equalization of the $\mathrm{Cs}^{+} \ldots \mathrm{O}$ distances between those observed (a) with both oxygens in the nitrobenzenide anionic moiety (3.061-3.326 $\AA$ ) and (b) with the neutral crown-ether ligand (3.103-3.427 $\AA$ ), in both crystalline modifications. $\underline{41}$ However, within the somewhat limited experimental precision, $\underline{42}$ the distortion in the molecular geometry of the nitrobenzenide moiety in (crown) $\mathrm{Cs}^{+} \mathbf{N B}^{-\bullet}$ is quite similar to that in the rubidium analogue (Table 1 ).

\section{ESR Spectra of Nitrobenzenide Ion Pairs.}

The various ion pairs of the nitrobenzene anion-radical afforded well-resolved ESR spectra in THF solutions at ambient temperatures, but even better spectral resolution could be achieved at $-30^{\circ} \mathrm{C}$. The corresponding hyperfine coupling constants of the potassium salts, both as contact and separated ion pairs, are listed in Table 2. Significant potassium splittings $\left({ }^{39} \mathrm{~K}, m_{l}=3 / 2\right)$ were not observed in either salt, even at $-30{ }^{\circ} \mathrm{C}$. Moreover, the mixed isotopic composition $\left({ }^{85} \mathrm{Rb}\right.$ and ${ }^{87} \mathrm{Rb}$ with $m_{l}=5 / 2$ and $3 / 2$ ), coupled with rather weak rubidium splittings led to ESR spectra too complex to render reliable determinations of the corresponding coupling constants in the contact ion pair: (crown)RB $\mathbf{N B}^{+} \mathbf{N}^{-}$. Essentially the same complications beset the contact ion pair for (crown) $\mathrm{Cs}^{+} \mathbf{N B}^{-}$.

Table 2. ESR Hyperfine Splittings (G) of Nitrobenzenide Ion Pairs ${ }^{a}$

\begin{tabular}{|l|l|l|l|l|}
\hline ion pair & $a_{\mathrm{N}}$ & $a_{\mathrm{p}}$ & $a_{\mathrm{o}}$ & $a_{\mathrm{m}}$ \\
\hline K(cryptand)+NB-・ & $9.23(9.49)$ & $4.15(4.15)$ & $3.38(3.38)$ & $1.01(1.01)$ \\
\hline (crown)K+NB & $10.08(10.20)$ & $4.07(4.01)$ & $3.39(3.38)$ & $1.05(1.05)$ \\
\hline
\end{tabular}


${ }^{a}$ At $-30^{\circ} \mathrm{C}$; room-temperature data are shown in parentheses.

Results in Table 2 show that there is a rather remarkable gain of roughly 10\% in the odd-electron (spin) population $\underline{43}$ at the nitrogen center in the contact ion pair relative to that in the separated ion pair-independent of temperature. It is also noteworthy that the corresponding change in odd-spin density on the phenyl ring is significantly less than that on the nitrogen center, with the spin population at the $p$-position even showing a perceptible decline.

\section{Electronic Spectra of Nitrobenzenide Ion Pairs.}

Unambiguous electronic spectra of the ion pairs for nitrobenzene anion-radical were measured in THF solutions prepared by the dissolution of pure crystalline salts in highly purified THF solvent under an argon atmosphere at $23^{\circ} \mathrm{C}$. The single broad (absorption) envelopes shown in Figure 6 are generally similar to that described by Kemula and $\mathrm{Sioda}^{23}$ and do not show any additional component beyond $500 \mathrm{~nm}$. This observation agrees with George's conclusion ${ }^{25}$ that the Tsubomura spectra ${ }^{24}$ must have been affected by impurities. Furthermore, the $\mathbf{N B}^{-\bullet}$ spectra reported by Suga and Aoyagui ${ }^{27}$ were also not free of contaminants.

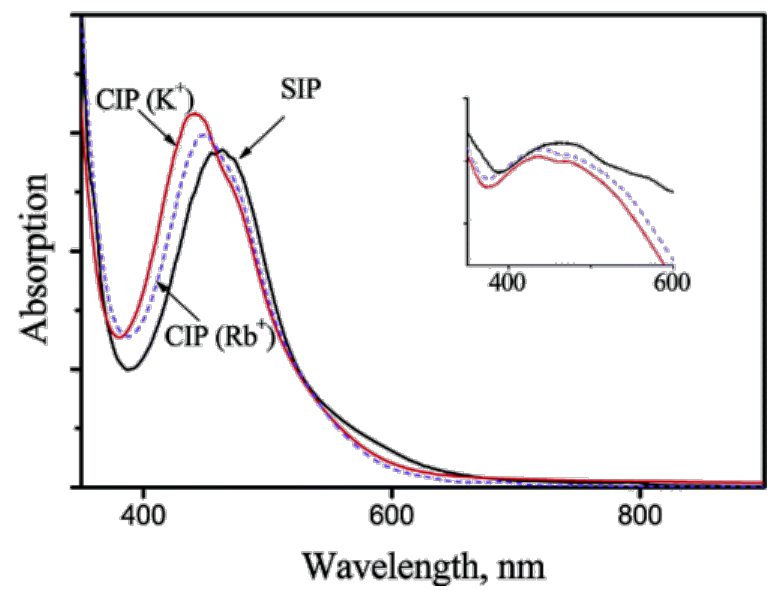

Figure 6 Electronic spectra of the nitrobenzenide salts in THF solutions: (black solid line)

K(cryptand) ${ }^{+} \mathbf{N B}^{-\bullet}$, (blue dashed line) (crown) Rb ${ }^{+} \mathbf{N B}^{-\bullet}$; (red solid line) (crown) $\mathrm{K}^{+} \mathbf{N B}^{-\bullet}$. Inset: Solid-state reflectance spectra of the same salts in dilute $\mathrm{KPF}_{6}$ matrix.

The single most prominent feature of the comparative UV-vis spectra in Figure 6 is the significant redshift in the electronic transition in the separated ion pair, $\mathrm{K}(\text { cryptand })^{+} \mathrm{NB}^{-\bullet}$ with $\lambda_{\max }=462 \mathrm{~nm}$, relative to that in either the corresponding contact ion pair (crown) $\mathrm{K}^{+} \mathrm{NB}^{-\bullet}$ with $\lambda_{\max }=443 \mathrm{~nm}$ or the contact ion pair from the large cation (crown) $\mathrm{Rb}^{+} \mathrm{NB}^{-\bullet}$ with $\lambda_{\max }=450 \mathrm{~nm}$. Most importantly, the same bands (albeit broadened) are observed in the solid-state reflectance spectra when the salts are diluted in $\mathrm{KPF}_{6}$ matrixes, as quantitatively listed in Table 3.

Table 3. Electronic (UV-Vis) Absorption Spectra of Nitrobenzenide Ion Pairs ${ }^{a}$

\begin{tabular}{|c|c|c|}
\hline ion pair & THF solution & $\mathrm{KPF}_{6}$ matrix \\
\hline $\mathrm{K}(\text { cryptand })^{+} \mathrm{NB}^{-\bullet}$ & $462 ; \varepsilon_{462}=1930$ & 470 \\
\hline (crown) $\mathrm{K}^{+} \mathrm{NB}^{-\bullet}$ & 443 (470); $\varepsilon_{443}=2300$ & $438(475)$ \\
\hline (crown)Rb+NB-• & $450(470) ; \varepsilon_{450}=2600$ & 445 (472) \\
\hline
\end{tabular}

${ }^{a} \lambda_{\max }$ in $\mathrm{nm}$ (shoulder in parentheses); uncertainty: $\pm 2 \mathrm{~nm}$ (solution) and $\pm 5 \mathrm{~nm}$ (solid). $\varepsilon$ in $\mathrm{M}^{-1} \mathrm{~cm}^{1}$. 


\section{Discussion}

\section{Ligand-Modulated Production of Separated and Contact Ion Pairs in Crystals.}

Multicentered coordination of metal cations with uncharged (polyether) ligands comes in two basic structural types-the 3-dimensional cryptands and the 2-dimensional crown ethers. The size of [2.2.2]cryptand is ideal for the complete encapsulation of the spherical potassium cation as shown in Figure 7A, and the size of 18-crown-6 is likewise ideal for the effective coordinative saturation of only the potassium hemisphere as shown in Figure 7B.
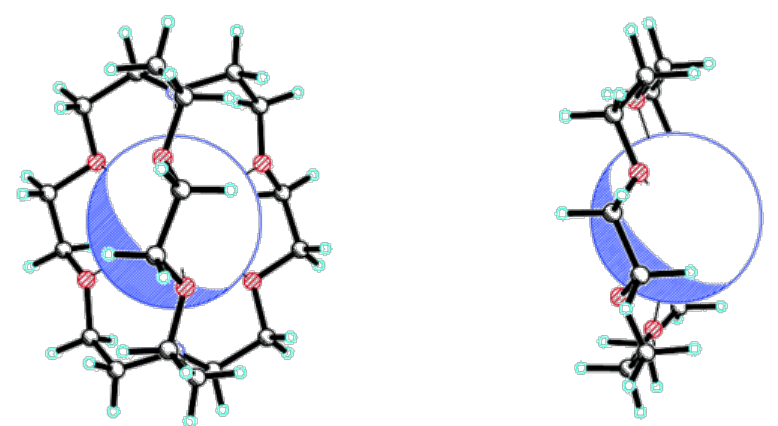

Figure 7 Space-filling representation of $\mathrm{K}^{+}$showing how $(\mathrm{A})$ its complete encapsulation by [2.2.2]cryptand effectively precludes direct interionic contact and (B) its nesting in 18-crown-6 fully shields only its back face.

X-ray crystallography of $\mathrm{K}(\mathrm{cryptand})^{+}$nitrobenzenide confirms the large interionic separation of the cationic potassium center from the primary seat of the negative charge on the $\mathrm{NO}_{2}$ group, and this (Figure 1) then defines a prototypical separated ion pair. By contrast, the available open face of (crown) $\mathrm{K}^{+}$allows intimate contact to the anionic nitro group via a pair of close $\mathrm{K}^{+} \ldots \mathrm{O}^{-}$contacts of 2.743 $\AA$, which are shorter than the regular coordination contacts $\mathrm{K}^{+} \ldots \mathrm{O}(\sim 2.85 \AA$ ), and this (Figure 3 ) then also defines the prototypical contact ion pair.

Having thus established the identity of the SIP vis à vis the CIP structure, we find that two important questions remain. First, what is the relevance of ion-pair structure established in the crystals to those extant in solution? Second, what is the electronic consequence(s) of such differences in their interionic separations?

\section{Ion-Pair Structures in Crystals versus Solution.}

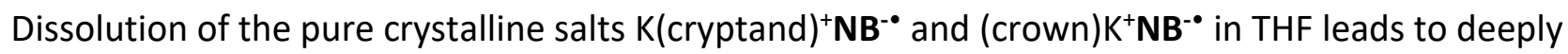
colored solutions showing a single absorption band in the visible region (Figure 6 ). These characteristic bands are sufficiently well-resolved to establish the unequivocal red shift from the CIP to the SIP structure (Table 3). That the same spectral characteristics are inherent in the solid-state spectra in Figure 6 (inset) and Table 3 (column 3) demonstrate that the same CIP/SIP dichotomy is also pertinent to the crystalline solid state, and vice versa. Moreover, the careful digital deconvolution of each of the absorption envelopes into three Gaussian components (see Experimental Section and Figures S1 and S2 in the Supporting Information) confirms this important conclusion.

Differences in ${ }^{14} \mathrm{~N}$ hyperfine splittings in the ESR spectra (Table 2) also distinguish CIP and SIP structures in solution. Unfortunately we were unable to establish the corresponding changes of the ${ }^{14} \mathrm{~N}$ 
hyperfine splittungs in the crystalline samples owing to loss of spectral resolution even at high dilutions in tetrabutylammonium hexafluorophosphate matrices.

\section{Electronic Structure of Paramagnetic Anions: Odd-Electron versusNegative-Charge Distribution in Nitrobenzenide Ion Pairs.}

The extensive probes of the electronic structure of nitrobenzene anion-radicals by ESR spectroscopy can provide accurate measures of $\pi$-electron spin-density distribution at various anionic positions. ${ }^{43}$ Since the latter follows directly from 1-electron accession to the nitrobenzene acceptor, it is reasonable to assume that such an (odd-electron) spin delocalization parallels the (negative) charge distribution as independently determined by bond-length changes (X-ray crystallography). However, the direct comparison of the ESR data summarized in Table 2 with the X-ray crystallographic data in Table 1 shows some important anomalies. To reconcile the differences, let us first qualitatively consider structural changes in the context of simple valence-bond structures since these conveniently allow the ready visualization of both spin and charge delocalizations in nitrobenzenide ion pairs. For example, the complete $\pi$-electron delocalization in nitrobenzene anion radical seems at first glance to agree with the principal structures $\mathbf{A}-\mathbf{C}($ Chart 1$)$ originally proposed by Geske and Maki ${ }^{8}$ to explain the predominant (odd-electron) distribution of spin density over the nitrogen center as well as the orthoand para- postions in the phenyl ring. However, a more detailed analysis shows the inadequacy of this simple representation since the set of $\mathbf{A}-\mathbf{C}$ structures cannot accommodate the structural changes established by X-ray crystallographic analysis in the formation of various ion pairs between $\mathbf{N B}^{-\bullet}$ and alkali-metal cations. Thus, a closer consideration reveals that any combination of resonance structures $\mathbf{A}-\mathbf{C}$ is charge-localized since they all contain six $\pi$ electrons associated with the phenyl ring and five $\pi$ electrons associated with the negatively charged nitro group. In other words, charge delocalization does not necessarily follow the spin delocalization in nitrobenzene anion-radical. With respect to Coulombic interactions, resonance structures $\mathbf{A}-\mathbf{C}$ are identical, and the associative energy with the positively charged alkali-metal ion should be invariant, leaving their relative contributions to the ion-paired structures independent of the associated cation (and polyether ligand). Clearly, other resonance structures need to be introduced-the most obvious choices being $\mathbf{D}$ and $\mathbf{E}$ (Chart 2), which represent permutations between anionic and radical structures $\mathbf{B}$ and $\mathbf{C}$, respectively. These $\pi$ -

conjugated structures involve spin localization on the oxygen atoms and transfer of negative charge to the phenyl ring. Such an intramolecular charge-transfer agrees with quantum-mechanical calculations, ${ }^{10}$ in which the conjugated structures $\mathbf{D}$ and $\mathbf{E}$ dominate the distribution of spin density in nitrobenzene anion-radical and can account for $40 \%$ of the spin population. The contribution of the nonconjugated form $\mathbf{A}$ with the electron spin localized at nitrogen is less, being only $24 \%$. The residual $36 \%$ corresponds to the array of conjugated and nonconjugated forms with the unpaired electron distributed over the phenyl ring as in resonance structures $\mathbf{F}$ and $\mathbf{G}$, together with aforementioned $\mathbf{B}$ and $\mathbf{C}$.

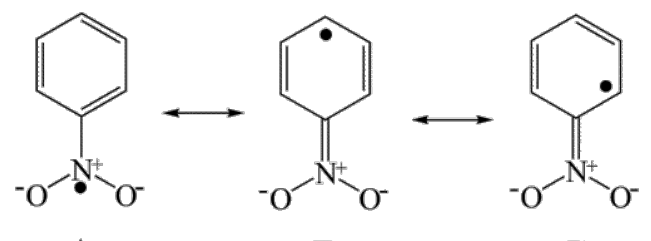

A

B

C

Chart 1 


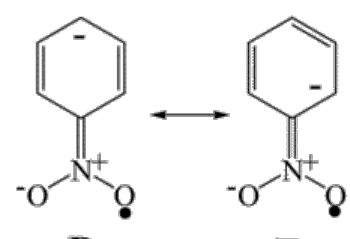

D

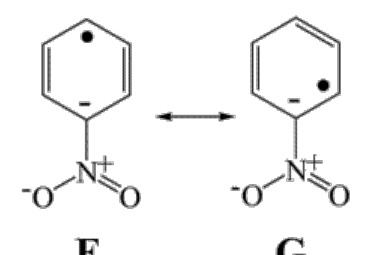

G

Chart 2

We believe that structural changes of the nitrobenzenoid moiety accompanying the ion-pairing can be more accurately described by the major contributions from resonance structures $\mathbf{A}, \mathbf{D}$, and $\mathbf{E}$, in which coordination of positively charged cations will better stabilize the nonconjugated structure $\mathbf{A}$ (with the predominant negative charge on the nitro group) compared to the conjugated structures $\mathbf{D}$ and $\mathbf{E}$ (with the electrically neutral nitro group). Thus, the loss of conjugation detected by bond-length changes from the X-ray crystallographic analysis of the contact ion pairs but increased spin population on the nitrogen center according to the ESR data are characteristic of resonance structure $\mathbf{A}$. Furthermore, the increased contribution of the nonconjugated form Aaccounts for the observed hypsochromic shift in the electronic spectra of the contact ion pairs since the SOMO localized on the nitro group accommodates both increased spin and charge density.

Finally, it is important to recognize that contact ion pairs also involve (a) measurable hyperfine splittings from the alkali metal in the ESR spectra ${ }^{11}$ and (b) increased noncoplanarity in NB- coordination with decreasing metal-ion size in the order $\mathrm{Cs}^{+}<\mathrm{Rb}^{+}<\mathrm{K}^{+}$, as crystallographically measured by the dihedral angle $\alpha \cdot \frac{44 a}{}$ Although such a partial charge-transfer and spin delocalization onto the alkali metal can be accounted for by contribution from $\sigma$-bonding, ${ }^{44 b}$ alternative mechanisms including spin polarization must also be considered.

\section{Summary and Conclusions}

Pure crystalline (alkali-metal) salts of nitrobenzene anion radical ( $\mathbf{N B}^{-\bullet}$ or nitrobenzenide) have been prepared and structurally characterized by X-ray crystallographic analysis as both the separated ion pair (SIP) and the contact ion pair (CIP). Thus, the ORTEP diagram in Figure 1 establishes the long interionic separation of $\sim 6 \AA$ between the nitrobenzenide anion and the potassium cation completely entombed by [2.2.2]cryptand which serves as its lipophilic sheath to enforce the ion-pair separation. By using a somewhat related synthetic strategy, the macrocyclic polyether ligand 18-crown-6 coordinatively insulates only the back hemisphere of potassium cation to leave its front face available for direct chelation to the negatively charged nitro group in the contact ion pair (crown) $\mathrm{K}^{+} \mathrm{NB}^{-\bullet}$ shown in Figure 3.

The successful isolation of these highly air-sensitive salts provides us the unique opportunity now to establish unambiguously the requisite reliable ESR and UV-vis spectral data of both ionically associated and separated $\mathbf{N B}^{-}$, heretofore unallowed. Quantitative comparison of these spectral data with precise structural parameters from X-ray crystallography at $-150{ }^{\circ} \mathrm{C}$ (with typical experimental uncertainties < $0.3 \mathrm{pm}$ ) leads to unusual insight into the electronic/charge delocalization in nitrobenzenide ion pairs with $\mathrm{K}^{+}, \mathrm{Rb}^{+}$, and $\mathrm{Cs}^{+}$countercations in the following ways. 


\section{First.}

In the separated ion pair $\mathrm{K}$ (cryptand) ${ }^{+} \mathrm{NB}^{-\bullet}$, the $\mathrm{C}-\mathrm{N}$ bond length of $1.383 \AA$ in the $\mathbf{N B}^{-\bullet}$ moiety is half that for a nonconjugated $\mathrm{C}-\mathrm{N}$ single bond $(1.477 \AA)$ and that for a localized $\mathrm{C}==\mathrm{N}$ double bond $(1.280$ $\AA)$. Such an intermediate bond length signifies that $\pi$-electron delocalization between the benzene ring and the nitro substituent is almost complete (95\%) in "free" nitrobenzenide anion. Upon its conversion to the contact ion pair (crown) $\mathrm{K}^{+} \mathrm{NB}^{-\bullet}$, the $\pi$ conjugation drops sharply to $75 \%$ as shown by the increased $\mathrm{C}-\mathrm{N}$ bond length of $1.403 \AA$ in the direct $\mathrm{K}^{+} \ldots \mathrm{O}^{-}$bindings. Furthermore, it then rises slightly to $85 \%$ in the contact ion pair (crown) $\mathrm{Rb}^{+} \mathrm{NB}^{-\bullet}$ owing to decreased metal-ion binding to the larger rubidium cation.

\section{Second.}

ESR spectra of the contact ion pairs of $\mathbf{N B}^{\bullet}$ show experimentally significant increases in nitrogen hyperfine splittings concomitant with corresponding decreases in the hydrogen hyperfine splittings relative to those found in the separated ion pair. The change corresponds to the buildup of electron spin density on the nitro group with its simultaneous depletion over the benzenoid ring of the nitrobenzenide anionic moiety as a result of its direct coordination to the alkali metal $\left(\mathrm{K}^{+}\right)$.

\section{Third.}

The electronic (UV-vis) absorption band of separated NB$^{-\bullet}$ at $\lambda_{\max }=462 \mathrm{~nm}$ suffers a measurable blue shift upon its conversion to the contact ion pairs with $\mathrm{K}^{+}$and $\mathrm{Rb}^{+}$with $\lambda_{\max }=443$ and $450 \mathrm{~nm}$, respectively. Such hypsochromic shifts in contact ion pairs coincide with the decreased energy of the electronic (SOMO-LUMO) transition accompanying spin/charge delocalization in the separated ion pair.

The considerable differences in the foregoing (X-ray, ESR, and UV-vis) facets of ion pairing result from reverse charge transfer to the nitro substituent from the benzenoid ring in $\mathbf{N B}^{-\bullet} . \underline{45}$ As such, the effect is induced by the approaching cation and accompanied by diminished $\pi$ conjugation due to partial (SOMO) localization on the nitro substituent. ${ }^{44 b}$

Most importantly, this crystallographic study provides unambiguous experimental evidence that deepseated structural changes accompany the interconversion of a contact ion pair and a separated ion pair beyond that ordinarily based upon solely electrostatic (Coulombic) considerations, as heretofore invoked. As such, it yields valuable insight into the more general problem on the relationship between ion-pair structure and chemical reactivity. We hope the direct (quantitative) bearing of these conclusions on reactivity will be the subject of further studies.

\section{Experimental Section}

\section{Materials.}

Metallic potassium, rubidium, and cesium from Aldrich were stored in a drybox and used without additional purification. 18-Crown-6 (crown) and 4,7,13,16,21,24-hexaoxa-1,10-

diazabicyclo[8.8.8] hexacosane (cryptand) from Aldrich were also used directly. Nitrobenzene from Aldrich was distilled under an argon atmosphere and stored over activated molecular sieves ( $4 \AA$ ) prior to use. High-purity tetrahydrofuran and hexane from Merck were freshly distilled from sodium/benzophenone under an argon atmosphere and briefly stored over activated molecular sieve. 
(For hexane distillation, a few drops of diglyme were added to improve the solubility of the benzophenone anion-radical.)

\section{Preparation of the Salts of the Nitrobenzene Anion-Radical NB-•.}

Typically, a sample of nitrobenzene $(60 \mathrm{mg}, 2 \mathrm{mmol}$ ) with a stoichiometric amount $(2 \mathrm{mmol}$ ) of the dissolved complexon (either crown or cryptand) was degassed three times by repeated freeze-pump-thaw cycles and sealed under an argon atmosphere. Potassium metal (19 mg, $2 \mathrm{mmol}$ ) was carefully cleaned mechanically in a glovebox under an argon atmosphere and placed in a welldried Schlenk tube $(50 \mathrm{~mL})$. The tube was slowly heated with an oil bath in vacuo until complete sublimation of the metal and mirror formation on the walls. A mixture of nitrobenzene and the complexing agent was dissolved in $15 \mathrm{~mL}$ of dry THF, and the solution was transferred into the Schlenk tube containing the metal mirror. An intense orange-red (in case of crown) or brown (in case of cryptand) coloration appeared immediately. The solution was allowed to stand at room temperature overnight, during which the metal mirror dissolved completely. The resulting deep-colored solution was carefully covered with a layer of dry hexane $(20 \mathrm{~mL})$ and placed for 2-3 days in a refrigerator maintained at $-50^{\circ} \mathrm{C}$. The reaction batch typically yielded 5-10 mg of well-formed crystals growing on the walls where the solvents mixed. The highly air-sensitive, dark red/brown crystals were carefully collected and then used for the X-ray structural studies as well as (after dissolving in dry THF) for ESR and UV/vis spectroscopic measurements. The rubidium and cesium salts were prepared in a similar way. Caveat. Anion-radical salts of nitrobenzene may be explosive.

\section{X-ray Crystallography.}

The single crystals of the anion-radical salts were obtained at $-50{ }^{\circ} \mathrm{C}$ by the slow diffusion of hexane carefully layered on the top of the corresponding saturated THF solutions. The intensity data for all the compounds were collected with the aid of a Siemens/Bruker SMART diffractometer equipped with an APEX CCD detector using Mo K $\alpha$ radiation $(\lambda=0.71073 \AA)$, at $-150^{\circ} \mathrm{C}$. In all cases, a semiempirical absorption correction was applied. $\underline{47}$ The structures were solved by direct methods $\underline{48}$ and refined by full-matrix least-squares procedures $\underline{49}$ with IBM Pentium and SGI $\mathrm{O}_{2}$ computers (see Table 4). (The Xray structure details of various compounds are on deposit and can be obtained from the Cambridge Crystallographic Data Center in the U.K.)

Table 4. Crystallographic Parameters and the Details of the Structure Refinements

\begin{tabular}{|c|c|c|c|c|c|}
\hline param & $\begin{array}{l}\mathrm{K}(\text { cryptand })^{+} \mathrm{N} \\
\mathrm{B}^{-}\end{array}$ & $\begin{array}{l}(\text { crown }) K^{+} N \\
\mathrm{~B}^{-}\end{array}$ & $\begin{array}{l}\text { (crown) Rb }{ }^{+} \mathbf{N} \\
\mathrm{B}^{-}\end{array}$ & $\begin{array}{l}{\left[(\text { crown }) \mathrm{Cs}^{+} \mathrm{NB}^{-}\right.} \\
]_{2}\end{array}$ & $\begin{array}{l}{\left[(\text { crown }) \mathrm{Cs}^{+} \mathrm{NB}^{-}\right.} \\
]_{2} \cdot 2 \mathrm{THF}\end{array}$ \\
\hline formula & $\mathrm{C}_{24} \mathrm{H}_{41} \mathrm{KN}_{3} \mathrm{O}_{8}$ & $\mathrm{C}_{18} \mathrm{H}_{29} \mathrm{KNO}_{8}$ & $\mathrm{C}_{18} \mathrm{H}_{29} \mathrm{NO}_{8} \mathrm{Rb}$ & $\mathrm{C}_{36} \mathrm{H}_{58} \mathrm{Cs}_{2} \mathrm{~N}_{2} \mathrm{O}_{16}$ & $\mathrm{C}_{44} \mathrm{H}_{74} \mathrm{Cs}_{2} \mathrm{~N}_{2} \mathrm{O}_{18}$ \\
\hline$M_{r}$ & 538.70 & 426.52 & 472.89 & 1040.66 & 1184.88 \\
\hline space group & $P 2 / n$ & Pnma & $P 2_{1} / n$ & $C 2 / c$ & $P \mathbf{I}$ \\
\hline$a(\AA)$ & $15.7997(8)$ & $8.5003(6)$ & $10.6000(5)$ & $26.220(2)$ & $8.5177(5)$ \\
\hline$b(\AA)$ & $10.1130(5)$ & $14.361(1)$ & $7.6557(4)$ & $8.3768(5)$ & $12.4319(7)$ \\
\hline$c(\AA)$ & 17.4795(9) & $17.573(1)$ & $26.779(1)$ & $22.305(1)$ & $26.192(1)$ \\
\hline$\alpha$ (deg) & 90 & 90 & 90 & 90 & 99.078(1) \\
\hline$\beta$ (deg) & $98.022(1)$ & 90 & 97.338(1) & $108.334(1)$ & $93.002(1)$ \\
\hline$Y$ (deg) & 90 & 90 & 90 & 90 & $102.619(1)$ \\
\hline$V\left(\AA^{3}\right)$ & $2765.6(2)$ & $2145.2(3)$ & $2155.3(2)$ & $4650.3(5)$ & 2661.7(3) \\
\hline
\end{tabular}




\begin{tabular}{|l|l|l|l|l|l|}
\hline$Z$ & 4 & 4 & 4 & 4 & 2 \\
\hline$D_{c}\left(\mathrm{~g} \mathrm{~cm}^{-3}\right)$ & 1.294 & 1.321 & 1.457 & 1.486 & 1.438 \\
\hline$N_{\text {ref }}($ collcd) & 29934 & 20859 & 23516 & 25470 & 28877 \\
\hline$R_{\text {int }}$ & 0.0171 & 0.0335 & 0.0279 & 0.0624 & 0.0222 \\
\hline $\begin{array}{l}N_{\text {ref }} \text { (indpen } \\
\text { d) }\end{array}$ & 8851 & 3654 & 6944 & 7502 & 16475 \\
\hline $\begin{array}{l}N_{\text {ref }}[I>2 \sigma(I) \\
]\end{array}$ & 7867 & 2844 & 5341 & 4358 & 12953 \\
\hline R1 & 0.0389 & 0.0480 & 0.0355 & 0.0518 & 0.0399 \\
\hline WR2 & 0.1042 & 0.1222 & 0.0801 & 0.1085 & 0.0960 \\
\hline
\end{tabular}

\section{ESR Measurements.}

The electron spin-resonance measurements were performed on a Bruker ESP-300 X-band spectrometer with $100 \mathrm{kHz}$ field modulation, $0.2 \mathrm{G}$ modulation amplitude, and $20 \mathrm{~mW}$ microwave power. The THF solutions were prepared under an argon atmosphere in a Schlenk tube and were transferred into a quartz ESR tube ( $2 \mathrm{~mm}$ diameter). The tube was placed in a quartz Dewar set in the center of a rectangular cavity, with the temperature regulated by an IBM control unit within $0.5^{\circ}$. Dry compressed nitrogen was pumped through the cavity to avoid any condensation of adventitious moisture at the low $\left(-30^{\circ} \mathrm{C}\right)$ temperature. The calculation of hyperfine splitting constants was carried out by the computer simulation of the ESR spectra with Bruker WINEPR Simfonia program (version 1.25).

\section{Measurement of Electronic Spectra.}

All spectroscopic measurements were performed under an argon atmosphere in a 1-mm quartz cuvette on either a Hewlett-Packard 8453 diode-array or a Varian Cary 5 spectrometer. In each case, freshly prepared THF solutions of the corresponding anion-radical salts were made up in a rigorously air-free drybox. For diffuse-reflectance measurements, $15 \mathrm{mg}$ of the corresponding $\mathbf{N B}^{-\bullet}$ salt was carefully ground with $800 \mathrm{mg}$ of $\mathrm{KPF}_{6}$ under an argon atmosphere. The molar extinction coefficient for the separated NB $^{-\bullet}$ anion-radical was determined as $\varepsilon_{462}=1.93 \times 10^{3} \mathrm{M}^{-1} \mathrm{~cm}^{-1}$, i.e., slightly higher than an earlier estimate $\left(1.5 \times 10^{3} \mathrm{M}^{-1} \mathrm{~cm}^{-1}\right){ }^{23}$ Careful scrutiny of the absorption envelopes in Figure 6 showed that each consisted of at least three Gaussian components, and quantitative deconvolution (correlation coefficient $>0.999$ and $\chi^{2}<0.01$ ) resulted in the precise location of the principal band $\mathrm{I}$, together with minor components II and III which are listed in the order of their absorption maxima, together with the bandwidth at half-maximum in parentheses (in $10^{3} \mathrm{~cm}^{-1}$ ), as follows: THF solution of (crown)K+NB-• 22.7 (3.64), 20.8 (0.83), 19.3 (2.96), (crown)Rb+NB-• 22.6 (3.16), 20.8 (0.97), 19.9 (3.63), K(cryptand) NB $^{-\bullet} 22.3$ (3.11), 20.8 (1.57), 19.5 (4.86); KPF 6 matrix of (crown) ${ }^{+} \mathbf{N B}^{-\bullet} 23.5$ (7.20), 19.0 (3.54), 14.9 (5.00), (crown)Rb+NB-• 23.2 (7.57), 19.1 (3.13), 17.6 (1.90), K(cryptand) NB $^{-\bullet} 21.7$ (9.78), 16.4 (2.60), 14.9 (0.53).

\section{Supporting Information Available}

Figures S1 and S2, showing the Gaussian deconvolutions of the UV-Vis spectra (Figure 6) in THF solution and in crystalline solid state (KPF6 matrix) and five X-ray crystallographic files in CIF format. This material is available free of charge via the Internet at http://pubs.acs.org. 


\section{Acknowledgment}

We thank S. V. Rosokha for the Gaussian deconvolutions/preparation of Figure 6 and the Robert A. Welch Foundation and the National Science Foundation for financial support.

\section{References}

$\underline{1}$ (a) Szwarc, M., Ed. Ions and lon Pairs in Organic Reactions; Wiley-Interscience: New York, 1972; Vols. 1 and 2. (b) Gordon, J. E. Organic Chemistry of Electrolyte Solutions; Wiley: New York, 1975. (c) Loupy, A.; Tchoubar, B. Effets des Sales en Chimie Organque et Organometallique; Dunod Université: Paris, 1988. (d) Kaiser, E. T.; Kevan, L. Radical lons; Interscience: New York, 1968. (e) Historically, ion-pair terminology in the chemical literature is rather vague/confusingcontact ion pairs having been interchangeably referred to as tight ion pairs, intimate ion pairs, etc., and separated ion pairs as loose ion pairs, solvent-separated ion pairs, etc., depending on the context in which they were employed.

$\underline{2}$ See also: (a) Reed, C. A.; Kim, K.-C.; Stoyanov, E. S.; Stasko, D.; Tham, F. S.; Mueller, L. J.; Boyd, P. D. W. J. Am. Chem. Soc.2003, 125, 1796. (b) Guha, C.; Chakraborty, M.; Karanjai, S.; Das, B. J. Phys. Chem. B2003, 107, 12814. (c) Vokin, A. I.; Shulunova, A. M.; Khil'ko, M. Y.; Lopyrev, V. A.; Turchaninov, V. K. Russ. J. Gen. Chem. 2003, 73, 1137. (d) Jones, J. W.; Gibson, H. W. J. Am. Chem. Soc.2003, 125, 7001. (e) Peters, S. J.; Turk, M. R.; Kiesewetter, M. K.; Reiter, R. C.; Stevenson, C. D. J. Am. Chem. Soc. 2003, 125, 11212. (f) Bockman, T. M.; Kochi, J. K. New J. Chem.1992, 16, 39. (g) Naidoo, K. J.; Lopis, A. S.; Westra, A. N.; Robinson, D. J.; Koch, K. R. J. Am. Chem. Soc.2003, 125, 13330. (h) Zuccaccia, C.; Bellachioma, G.; Cardaci, G.; Macchioni, A. J. Am. Chem. Soc.2001, 123, 11020. (j) Nishinaga, T.; Yamazaki, D.; Stahr, H.; Wakamiya, A.; Komatsu, K. J. Am. Chem. Soc.2003, 125, 7324. (k) Bock, H.; Herrmann, H. F.; Fenske, D.; Goesmann, H. Angew. Chem., Int. Ed. Engl.1988, 27, 1067.

$\underline{3}$ (a) Thermodynamics (and kinetics) justification for two principal types of such ion pairs is presented by Szwarc in ref 1, Vol. 1 (Chapter 1). (b) Our operational classification of the contact ion pair herein requires direct interionic contact between the positive and negative centers (within their van der Waals radii). By contrast, such a direct electrostatic interaction between cation/anion centers is modified in the separated ion pair by intervention of one or more solvent, ligand, etc.

4 (a) Pocker, Y.; Spyridis, G. T. J. Am. Chem. Soc.2002, 124, 7390. (b) Wang, D. Z.; Streitwieser, A. J. Org. Chem.2003, 68, 8936. (c) Zhao, P.; Collum, D. B. J. Am. Chem. Soc.2003, 125, 4008. (d) Sun, X.; Winemiller, M. D.; Xiang, B.; Collum, D. B. J. Am. Chem. Soc.2001, 123, 8039. (e) Thompson, A.; Corley, E. G.; Huntington, M. F.; Grabowski, E. J. J.; Remenar, J. F.; Collum, D. B. J. Am. Chem. Soc.1998, 120, 2028. (f) John, M.; Auel, C.; Behrens, C.; Marsch, M.; Harms, K.; Bosold, F.; Gschwind, R. M.; Rajamohanan, P. R.; Boche, G. Chem.Eur. J.2000, 6, 3060. (g) Gschwind, R. M.; Rajamohanan, P. R.; John, M.; Boche, G. Organometallics2000, 19, 2868. (h) Hofmans, J.; Maeseele, L.; Wang, G.; Janssens, K.; Van Beylen, M. Polymer2003, 44, 4109. (j) Sun, X. F.; Collum, D. B. J. Am. Chem. Soc.2000, 122, 2459. (k) Leung, S. S. W.; Streitwieser, A. J. Am. Chem. Soc.1998, 120, 10557.

$\underline{5}$ Although examples of both contact ion pairs as well as separated ion pairs are rife in the organic crystallography literature, we were unable to find any comparative quantitative analysis of their unique structural identities.

6 Chu, T. L.; Pake, G. E.; Paul, D. E.; Townsend, J.; Weissman, S. I. J. Phys. Chem.1953, 57, 504.

Z (a) Ward, R. L.; Klein, M. P. J. Chem. Phys.1958, 28, 518. (b) Ward, R. L. J. Chem. Phys.1959, 30, 852. (c) Ward, R. L. J. Am. Chem. Soc.1961, 83, 1296.

8 Geske, D. H.; Maki, A. H. J. Am. Chem. Soc.1960, 82, 2671.

9 Smentowski, F. J.; Stevenson, G. R. J. Chem. Soc.1968, 90, 4661.

10 Rieger, P. H.; Fraenkel, G. K. J. Chem. Phys.1963, 39, 609. 
11 The latter derived from the ESR studies of Ward, ${ }^{7}$ who first mentioned the additional sodium splittings in $\mathrm{Na}^{+} \mathbf{N B}^{-\bullet}$ and later by Gross and Barnes, ${ }^{12}$ who observed the potassium splittings of $\mathrm{K}^{+} \mathrm{NB}^{-\bullet}$ in DME solutions.

12 (a) Gross, J. M.; Barnes, J. D. Chem. Commun.1968, 50. See also: (b) Jones, M. T.; Zeller, D. E. J. Chem. Phys.1968, 48, 3341. (c) Jones, M. T.; Feighan, M. J. J. Chem. Phys.1968, 49, 5549.

13 Ling, C.-Y.; Gendell J. J. Chem. Phys.1967, 47, 3475.

14 (a) The influence of environment on distribution of electron (spin) density in NB-• anion-radicals was extensively studied for protic solvents revealing that the nitrogen splitting $a_{\mathrm{N}}$ of $\mathbf{N B}^{-\bullet}$ exhibits an extremely large increase from 10.3 to $13 \mathrm{G}$ and more in aqueous DMF, ethanol, acetonitrile, and pyridine. The effect is likely caused by protonation of nitro group since the shifts in $a_{\mathrm{N}}$ correlate quantitatively with dissociation constants of the protic solvents. ${ }^{15}$ For proton splittings, no significant solvent effect was found, however. ${ }^{16}$

15 (a) Ludwig, P.; Layloff, T.; Adams, R. N. J. Am. Chem. Soc.1964, 86, 4568. (b) Kolker, P. L.; Waters, W. A. J. Chem. Soc.1964, 1136. (c) Zhenghao, W.; Zhibin, H. Sci. China, Ser. B1988, 31, 531 and references therein.

16 (a) Ata, M.; Suzuki, Y.; Kubozono, Y.; Aoyagi, M.; Gondo, Y. Chem. Phys. Lett.1989, 157, 19. For the effect on ${ }^{17}$ O hyperfine splittings in aqueous DMF solutions, see: (b) Gulick, W. M.; Geske, D. H. J. Am. Chem. Soc.1965, 87, 4049.

17 Polarographically, it was shown early that the nature of the cation in the supporting electrolyte noticeably affected the reduction potentials of nitrobenzene derivatives. ${ }^{18}$ In the systematic study of Kalinowski, ${ }^{19}$ the reduction potential $E_{1 / 2}$ of NB was shown to correlate linearly with the ionic potential of the counterion in DMF solutionsdecreasing from $1.13 \mathrm{~V}$ (VS SCE) in the presence of $\mathrm{Et}_{4} \mathrm{~N}^{+}$to $1.03 \mathrm{~V}$ in the presence of $\mathrm{Li}^{+}$and the electrochemical reduction of NB was also studied by Krygowski et al., ${ }^{20}$ who calculated the association constants of the corresponding $\mathrm{NB}^{-\bullet} \mathrm{CIPs}$ to increase from $\log \left(K_{\text {ass }}\right)=2.30$ to 6.78 , respectively. Various aspects of the reductive behavior of NB have been studied by different authors. ${ }^{21}$

18 Holleck, L.; Becher, D. J. Electroanal. Chem.1962, 4, 321.

19 Kalinowski, M. K. Chem. Phys. Lett. 1971, 8, 378.

20 Krygowski, T. M.; Lipsztajn, M.; Galus, Z. J. Electroanal. Chem.1973, 42, 261.

21 (a) Jensen, S.; Parker, V. D. Chem. Commun. 1974, 367. (b) Meisel, D.; Neta, P. J. Am. Chem. Soc.1975, 97, 5198. (c) Smith, W. H.; Bard, A. J. J. Am. Chem. Soc.1975, 97, 5203. (d) Chauhan, B. G.; Fawcett, W. R.; Lasia, A. J. Phys. Chem.1977, 81, 1476. (e) Fawcett, W. R.; Lasia, A. J. Phys. Chem.1978, 82, 1114.

22 (a) Selivanov, B. A.; Shteingarts, V. D. Russ. J. Org. Chem.1995, 31, 1276. (b) Selivanov, B. A.; Shteingarts, V. D. Russ. J. Org. Chem.2001, 37, 1719. See also: (c) Nagelkerke, R.; Thatcher, G. R. J.; Buncel, E. Org. Biomol. Chem.2003, 1, 163. (d) Togashi, D. M.; Costa, S. M. B. New. J. Chem.2002, 26, 1774. (e) Vakarin, E. V.; Holovko, M. F.; Piotrowiak, P. Chem. Phys. Lett. 2002, 363, 7. (f) Gale, P. A. Coord. Chem. Rev.2003, 240, 191. (g) Tsuji, Y.; Mori, T.; Toteva, M. M.; Richard, J. P. J. Phys. Org. Chem.2003, 16, 484. (h) Trost, B. M.; Bunt, R. C. J. Am. Chem. Soc.1998, 120, 70.

23 Kemula, W.; Sioda, R. Nature1963, 197, 588.

24 Ishitani, A.; Kuwata, K.; Tsubomura, H.; Nagakura, S. Bull. Chem. Soc. Jpn.1963, 36, 1357.

25 Kalyanaraman, V.; Rao, C. N. R.; George, M. V. Tetrahedron Lett.1969, 55, 4889.

26 Chambers, J. Q.; Adams, R. N. Mol. Phys.1965, 8, 413.

27 Suga, K.; Aoyagui, S. Bull. Chem. Soc. Jpn.1987, 60, 2713.

28 For some reason, the authors of ref 27 mistakenly credited Lyons and Mackie for the spectroscopic measurements of $\mathbf{N B}^{-*}$ originally carried out by Kemula and Sioda. ${ }^{23}$

29 (a) Baik, M.-H.; Schauer, C. K.; Ziegler, T. J. Am. Chem. Soc.2002, 124, 11167. See also: (b) Kawabata, H.; Tachikawa, H. Phys. Chem. Chem. Phys. 2003, 5, 3587. (c) Nifant'ev, I. E.; Ustynyuk, L. Y.; Besedin, D. V. Organometallics2003, 22, 2619. 
30 For example, our varied attempts to reduce nitrobenzene with sodium and potassium mirrors consistently led to variably colored solutions from which only noncrystalline (tar-like) solids could be isolated. Byproducts were by and large unidentified, except in the case of $p$-dinitrobenzene reduction with potassium for which we were able to isolate (crystalline) potassium $p$-nitrophenolate and potassium nitrite, which were identified by X-ray analysis.

31 For representative examples of isolated ion pairs of aromatic anion-radicals via alkali-metal reductions, see: (a) Mooij, J. J.; Klaassen, A. A. K.; de Boer, E.; Degens, H. M. L.; van der Hark, T. E. M.; Noordik, J. H. J. Am. Chem. Soc.1976, 98, 680. (b) Jost, W.; Adam, M.; Enkelmann, V.; Muellen, K. Angew. Chem., Int. Ed. Engl.1992, 31, 878. (c) Janiak, C.; Hemling, H. Chem. Ber.1994, 127, 1251. (d) Bock, H.; Arad, C.; Naether, C.; Havlas, Z. Chem. Commun.1995, 2393. (e) Naether, C.; Bock, H.; Claridge, R. F. C. Helv. Chim.

Acta1996, 79, 84. (f) Naether, C.; Bock, H.; Havlas, Z.; Hauck, T. Organometallics1998, 17, 4707. (g) Bock, H.; Gharagozloo-Hubmann, K.; Slevert, M.; Prisner, T.; Havlas, Z. Nature2000, 404, 267. (h) Hitchcock, P. B.; Lappert, M. F.; Protchenko, A. V. J. Am. Chem. Soc.2001,123, 189.

32 Dietrich, B.; Lehn, J. M.; Sauvage, J. P.; Blanzat, J. Tetrahedron1973, 29, 1629.

33 Unfortunately, we have been unable as yet to obtain the highly desirable sodium and lithium salts in pure crystalline form by this general procedure.

34 Boese, R.; Blaser, D.; Nussbaumer, M.; Krygowski, T. M. Struct. Chem.1992, 3, 363.

35 (a) The degree of electronic delocalization between the nitro substituent and the phenyl ring can be calculated as ${ }^{36} q=2\left(d_{1}-d_{q}\right) /\left(d_{1}-d_{2}\right)$, where $d_{q}$ is the current length of the $\mathrm{C}-\mathrm{N}$ bond and $d_{1}$ and $d_{2}$ are standard bond lengths of the $\mathrm{C}-\mathrm{N}$ (unconjugated) single and double bonds, respectively. According to this relationship, the parameter $q=100 \%$ corresponds to the bond with the bond order 1.5 and with the length exactly intermediate between the double and single ones. (b) The accompanying quinonoidal distortion of the phenyl ring is given by the contraction of bond $\mathbf{d}$ and the corresponding elongation of bonds $\mathbf{c}$ and $\mathbf{e}$ (see scheme in Table 1). For the previous discussion of quinonoidal distortion, see: Lindeman, S. V.; Rosokha, S. V.; Sun, D.; Kochi, J. K. J. Am. Chem. Soc.2002, 124, 843.

36 Although there is an exponential dependence between the length $(d)$ of a chemical bond and its bond order (see: Pauling, L.Nature of the Chemical Bond; Cornell: Ithaca, NY, 1960; p 280), linear interpolation is acceptable for small variations of $d$.

37 Moriguchi, T.; Inoue, M.; Yasutake, M.; Sinmyozu, T.; Sakata, K.; Tsuge, A. J. Chem. Soc., Perkin Trans. 22001, 2084.

38 Allen, F. H.; Kennard, O.; Watson, D. G.; Brammer, L.; Orpen, A. G.; Taylor, R. J. Chem. Soc., Perkin Trans. 2 1987, S1.

39 Cram, D. J.; Trueblood, K. N. Top. Curr. Chem.1981, 98, 43.

40 For example, the close structural analogue of NB $^{-\bullet}$ taken as the benzoate anion also forms (somewhat) folded chelate rings in its ionic $\mathrm{Ba}^{2+}$ complex (Chekhlov, A. N.; Martynov, I. V. Dokl. Akad. Nauk SSSR1997, 357, 75), whereas it leads to planar chelate geometries in a variety of $\sigma$-bonded coordination complexes, e.g. with Ni" (Hursthouse, M. B.; New, D. B. J. Chem. Soc., Dalton Trans.1977, 1082), Ru"'(McGuiggan, M. F.; Pignolet, L. H. Cryst. Struct. Commun.1981, 10, 1227), or Sn'V (Tiekink, E. R. T. J. Organomet. Chem.1991, 408, 323).

41 The cesium salt crystallizes both as a discrete compound and as a THF solvate; see Experimental Section.

42 The partial molecular disorder in the cesium structures along with significant heavy-atom effects resulted in somewhat less precise geometrical parameters as compared with other structures (see Experimental Section).

43 For the quantitative (McConnell, McLauchlan) relationship between hyperfine coupling constants and oddelectron spin density, see: Wertz, J. E.; Bolton, J. R. Electron Spin Resonance; McGraw-Hall: New York, 1972.

$\underline{44}$ (a) In the latter regard, we expect the ion-pair geometries with coordinatively saturated cations such as tetraalkylammonium to show high degrees of $\pi$-character. (b) Qualitatively $\sigma$-bonding would involve resonance structures $\mathbf{H}$ and $\mathbf{J}$ to account for partial charge transfer and spin polarization. Although such 
an effect is commonly attributed to electrostatics, we tentatively associate it with partial $\sigma$ bonding between $\mathbf{N B}^{-\bullet}$ and the alkali-metal cation owing to the following (orbital) considerations. ${ }^{46}$ (i) The angular deviation of the cation from the mean plane of the coordinated nitro group in contact ion pairs decreases monotonically with cation size from $\alpha=55-58^{\circ}\left(\mathrm{Cs}^{+}\right)$, to $45^{\circ}\left(\mathrm{Rb}^{+}\right)$, and to $15^{\circ}\left(\mathrm{K}^{+}\right)$. Such a trend is expected for increasing charge localization due to the $\sigma$-character of the $\mathrm{M}^{+} \ldots \mathrm{O}^{-}$interaction and not necessarily from the electrostatics (which favors $\pi$ character). (ii) Perceptible hyperfine splittings that are measured in the ESR spectra of nitrobenzenide ion pairs result from partial spin transfer to the alkali metal. Such additional metal-ion splittings imply direct bindings and not necessarily electrostatic interactions.

$\underline{45}$ In terms of the qualitative valence-bond representation, reverse charge transfer is represented by changing the contributions for the two major structures $\mathbf{A}$ and $\mathbf{D} / \mathbf{E}$ in Charts 1 and 2, respectively.

46 As qualitatively visualized from the resonance structures in ref 44 .

47 Sheldrick, G. M. SADABS (Ver. 2.03)-Bruker/Siemens Area Detector Absorption and Other Corrections; Bruker/Siemens: Madison, WI, 2000.

48 Sheldrick, G. M. SHELXS 86-Program for Crystal Structure Solutions; University of Göttingen: Göttingen, Germany, 1986.

49 Sheldrick, G. M. SHELXL 93-Program for Crystal Structure Refinement; University of Göttingen: Göttingen, Germany, 1993. 